\title{
Cerebral Medulloepithelioma: A Rare Aggressive Brain Tumor in Child - A Case Report
}

\author{
Rohit Bansil ${ }^{1}$ Aman Kindra ${ }^{1}$ Nasim Mansoori ${ }^{2}$ Sumit Sinha ${ }^{2}$ Suryanarayanan Bhaskar ${ }^{1}$ \\ Poojan Agarwal ${ }^{3}$
}

${ }^{1}$ Department of Neurosurgery, PGIMER and Dr. RML Hospital, New Delhi, India

2 Department of Neurosurgery, All India Institute of Medical Sciences, New Delhi, India

${ }^{3}$ Department of Pathology, PGIMER and Dr RML Hospital, New Delhi, India

Address for correspondence Dr. Rohit Bansil, DNB, Department of Neurosurgery, PGIMER and Dr. RML Hospital, New Delhi, India (e-mail: banrohit1@gmail.com).

Indian J Neurosurg 2016;5:55-58.

\begin{abstract}
Keywords

- cerebral medulloepithelioma

- tumor

- brain

- child

Medulloepithelioma of the central nervous system (CNS) is a rare primitive neuroectodermal tumor (PNET) usually occurring in early childhood. It is a highly aggressive tumor with poor outcomes despite aggressive treatment. The ideal treatment appears to be gross total surgical resection, followed by radiation therapy. We report a case of a cerebral medulloepithelioma in a child with an aggressive tumor growth despite the gross total resection, who is surviving 1 year after diagnosis.
\end{abstract}

\section{Introduction}

Cerebral medulloepithelioma is a rare, highly malignant embryonal brain tumor, commonly seen in pediatric age group and carrying a very poor prognosis with a reported median survival of only 5 months with a propensity for progression, recurrence, and dissemination, despite therapy. ${ }^{1}$ We report a case of cerebral medulloepithelioma in a 9-year-old child who had an aggressive tumor growth after first surgery, and after second surgery, additionally received postoperative radiation therapy, and is now following up, 1 year after diagnosis, without any clinical evidence of tumor recurrence.

\section{Case Report}

A 9-year-old boy, presented with history of progressively worsening headache and weakness of left half of body for the last 5 days. The physical examination revealed the child to be conscious but disoriented and having left hemiparesis with papilledema bilaterally. There was a positive history of contact with tuberculosis in the family. The routine preoperative investigations were within normal limits, with the exception of erythrocyte sedimentation rate (ESR), which was $46 \mathrm{~mm}$. Computed tomographic (CT)

received

July 28, 2015

accepted

November 23, 2015

published online

February 24, 2016 scan and contrast magnetic resonance imaging (MRI) of the brain were suggestive of a large well-defined heterogeneously enhancing mass lesion in the right frontal and parietal region, with gross perilesional edema and severe mass effect (-Figs. 1 and 2 A-D). Craniotomy was done and gross total resection of the tumor mass was achieved. Peroperative, the tumor was well encapsulated with a clear plane with the normal brain parenchyma. The tumor was grayish yellow, caseous, firm in consistency, with no involvement of the overlaying dura. Per-operative impression was of a tuberculoma. Postoperatively, the child recovered, hemiparesis improved, and he was discharged on post-op day 6 , on five-drug antitubercular therapy.

The histopathology was suggestive of a highly cellular tumor, composed of nests, tubules, and trabecular arrangement of malignant cells, lined by pseudostratified epithelia, resembling primitive neural tube (-Figs. $\mathbf{3 A}$ and $\mathbf{B}$ ). Immunohistochemistry was positive for pan-cytokeratin, nestin, and vimentin (-Fig. 3C), suggestive of medulloepithelioma.

The patient, however, was lost to follow-up; hence he could not receive adjuvant radiotherapy.

The child was again brought to casualty after 3 months of the initial surgery in a state of altered sensorium. Plain CT
DOI http://dx.doi.org/ 10.1055/s-0036-1572375. ISSN 2277-954X. (c) 2016 Neurological Surgeons' Society of India
License terms

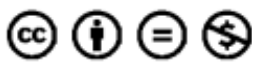




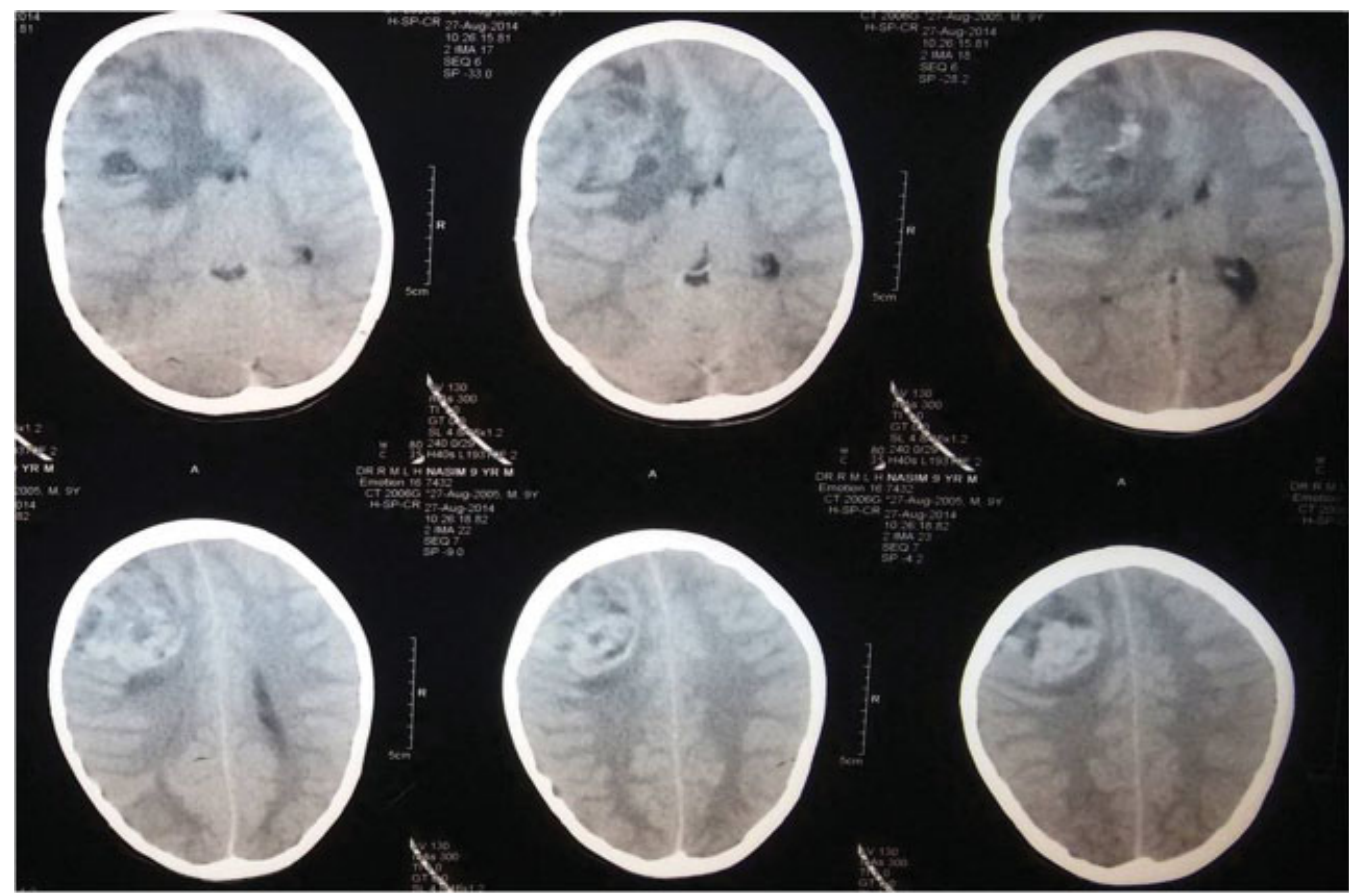

Fig. 1 Plain CT scan at admission.

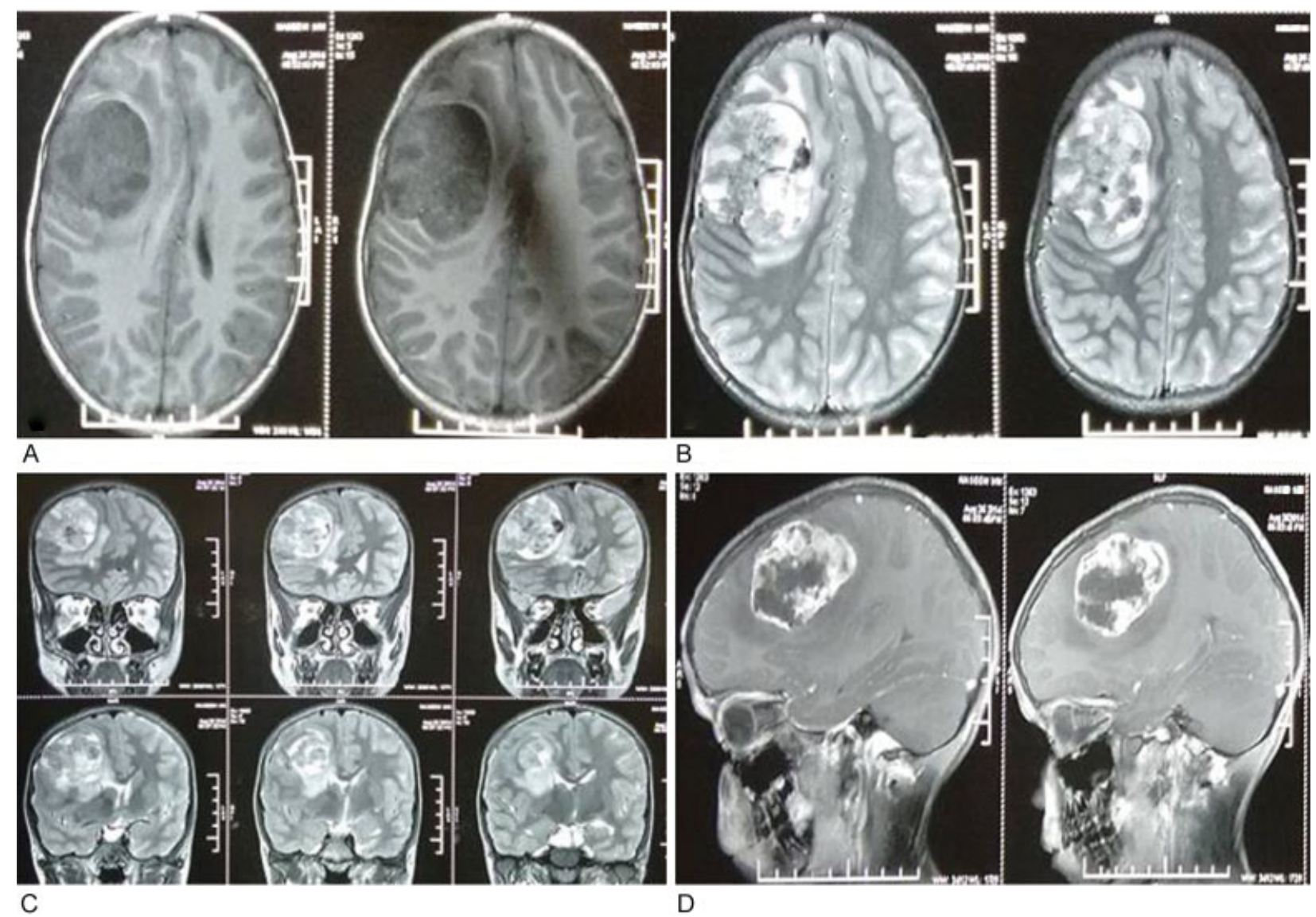

Fig. 2 MRI (A) T1 axial. (B) T2 axial. (C) T2 coronal. (D) Contrast. 

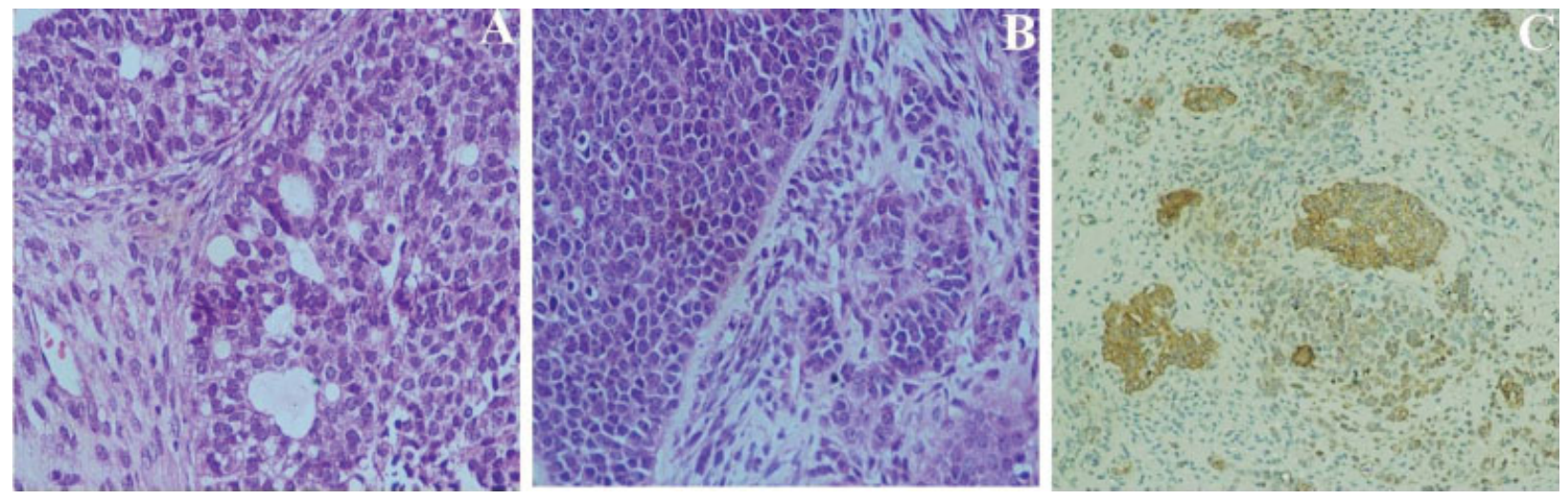

Fig. 3 (A) Tubules appreciated in tumor islands. (B) Solid tumor islands with adjacent cellular stroma. (C) Immunohistochemistry: Pancytokeratin-positive cells.

scan and contrast MRI done at that time was suggestive of an extensive tumor recurrence along with severe mass effect (-Fig. 4). He was reoperated and gross total resection achieved. MRI of the spine and lumbar cerebrospinal fluid (CSF) examination, done to rule out any dissemination of tumor, were unremarkable.

The histopathology report was once again suggestive of medulloepithelioma. He recovered well and received postoperative radiation therapy. The child attended the outpatient clinic 1 year after the diagnosis and was clinically not having any neurologic deficits and was attending school.

\section{Discussion}

The cerebral medulloepitheliomas were first described by Bailey and Cushing in 1926, as a separate entity of tumors. ${ }^{2}$ They are categorized as rare, highly malignant primitive neuroectodermal tumors (PNETs) (World Health Organization [WHO] grade IV). So far, only nearly 45 cases of cerebral medulloepitheliomas have been reported in the literature, with four cases reported from India. ${ }^{3-5}$ They usually manifest in the first decade of life ${ }^{6,7}$ and are occasionally seen in older patients, ${ }^{8}$ with an equal incidence in males and females. ${ }^{1}$ The

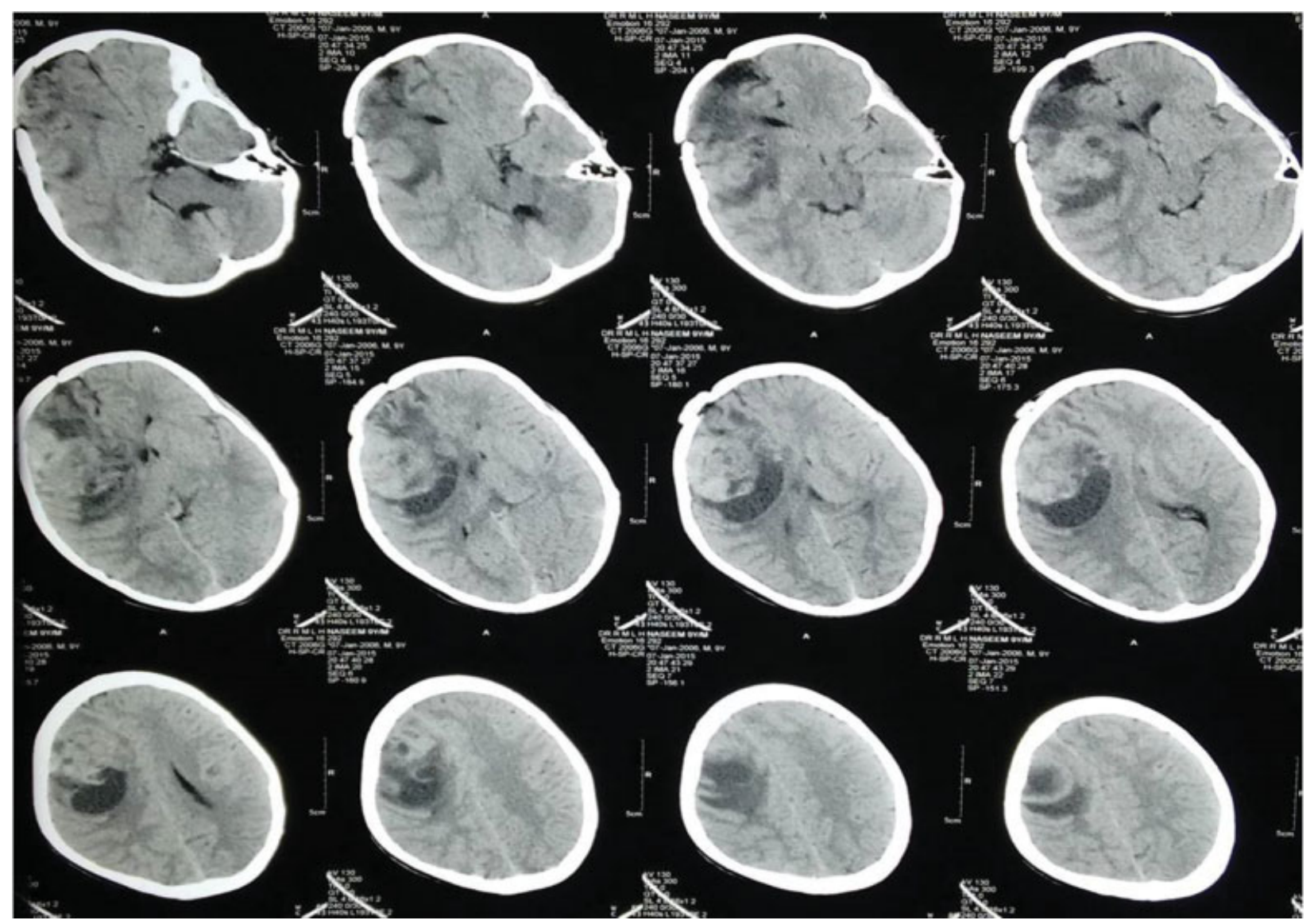

Fig. 4 Plain CT scan showing recurrence of tumor. 
natural history is of an aggressive type and the outcome in most cases is fatal despite treatment.

On CT scan, these tumors appear well circumscribed, isodense to hypodense to brain parenchyma with heterogeneous contrast enhancement, and on MRI, they are hypointense on $T_{1}$ and hyperintense on $T_{2}$ with no contrast enhancement. ${ }^{1,9}$ Our patient, however, showed a heterogeneous contrast enhancement on MRI, which is also reported by some other authors in their reports. ${ }^{4,10}$

On histopathology, the most distinguishing feature is the arrangement of pseudostratified columnar cells around a lumen, resting on a continuous basement membrane, mimicking a primitive neural tube. Immunohistochemically, these cells are positive for nestin and vimentin and positivity for cytokeratin indicates ependymal differentiation.

The ideal treatment of cerebral medulloepitheliomas is a gross total resection of the tumor followed by radiation therapy of the craniospinal axis with a local boost to cranium. ${ }^{1}$ The role of radiation therapy is clearly well established, with most of cases reported having a fairly long survival after postoperative radiotherapy. ${ }^{1,8}$ In our case also, the tumor initially recurred within 3 months without adjuvant radiotherapy; however, the child is tumor free after 1 year of second surgery and postoperative radiotherapy. Few authors have advocated the use of chemotherapy, but its efficacy in the treatment of medulloepithelioma remains to be determined. ${ }^{10}$ Only one case has been reported in the literature who survived more than 7 years after surgery, without any adjuvant therapy. ${ }^{11}$

\section{Conclusion}

Medulloepitheliomas must be considered as a differential diagnosis, whenever a PNET is suspected, particularly in children in their first decade. The approach toward management should be rather an aggressive one, with screening of craniospinal axis for dissemination of tumor and a gross total surgical resection of the tumor, followed by radiation therapy. The establishment of the utility and efficacy of chemotherapy in the management warrants further study.

\section{Conflict of Interest}

The authors report no conflict of interest concerning the materials or methods used in this report or the findings specified in this paper.

\section{Financial Disclosure}

None.

\section{Permission Requests}

None.

\section{Contributors' Statement}

The study was first conceived by Dr. Rohit Bansil, Dr. S. Bhaskar, and Dr. Aman Kindra. The pathological diagnostic help was provided by Dr. P. Agarwal. The manuscript was prepared by Dr. Rohit Bansil, Dr. Naseem Mansoori, and Dr. Sumit Sinha.

\section{Acknowledgments}

We thank Mr. Shanu and Mr. Akshay for technical assistance.

\section{References}

1 Molloy PT, Yachnis AT, Rorke LB, et al. Central nervous system medulloepithelioma: a series of eight cases including two arising in the pons. J Neurosurg 1996;84(3):430-436

2 Bailey P, Cushing H. A Classification of Tumors of the Glioma Group on a Histogenetic Basis with a Correlated Study of Progress. Philadelphia, PA: JB Lippincott; 1926:54-56

3 Müller K, Zwiener I, Welker $\mathrm{H}$, et al. Curative treatment for central nervous system medulloepithelioma despite residual disease after resection. Report of two cases treated according to the GPHO Protocol HIT 2000 and review of the literature. Strahlenther Onkol 2011;187(11):757-762

4 Sundaram C, Vydehi BV, Jaganmohan R J, Reddy AK. Medulloepithelioma: a case report. Neurol India 2003;51(4): 546-547

5 Syal R, Reddy S J, Kumar R, et al. Unusual clinical and MRI features of a cerebellopontine angle medulloepithelioma. Case report and review of literature. Pediatr Neurosurg 2006;42(5):299-303

6 Deck JH. Cerebral medulloepithelioma with maturation into ependymal cells and ganglion cells. J Neuropathol Exp Neurol 1969;28(3):442-454

7 Auer RN, Becker LE. Cerebral medulloepithelioma with bone, cartilage, and striated muscle. Light microscopic and immunohistochemical study. J Neuropathol Exp Neurol 1983; 42(3):256-267

8 Lolova I, Bojinov S, Ivanova A, Christov V. Cerebral medulloepithelioma. Histological and histochemical study of a case. J Neurol Sci 1972;15(2):173-182

9 Pang LM, Roebuck DJ, Ng HK, Chan YL. Sellar and suprasellar medulloepithelioma. Pediatr Radiol 2001;31(8):594-596

10 Matsumoto M, Horiuchi K, Sato T, et al. Cerebral medulloepithelioma with long survival. Neurol Med Chir (Tokyo) 2007;47(9):428-433

11 Vincent S, Dhellemmes P, Maurage CA, Soto-Ares G, Hassoun J, Ruchoux MM. Intracerebral medulloepithelioma with a long survival. Clin Neuropathol 2002;21(5):197-205 